\title{
Supply Chain Optimization under New Product Development and Emergence of Risks with Meta-Heuristic Approach
}

\author{
Ehsan Dehdar ${ }^{1}$ and Amir Azizi ${ }^{2}$ \\ 1,2Department of Industrial Engineering, Science and Research Branch, Islamic Azad University, Tehran, Iran. \\ Email: e.dehdar94@gmail.com ${ }^{1} \&$ azizi@ srbiau.ac.ir ${ }^{2}$
}

Copyright: () 2021 Ehsan Dehdar and Amir Azizi. This is an open access article distributed under the terms of the Creative Commons Attribution License, which permits unrestricted use, distribution, and reproduction in any medium, provided the original author and source are credited.

In this paper, a comprehensive multi-objective model has been proposed to optimize a supply chain when new product launches and risks emerge. In doing so, primarily, a set of risks and needed mitigation strategies are identified; secondly, the essential criteria of new product development (NPD) are introduced. These criteria are then weighted by the analytic hierarchy process (AHP) approach. Based on the calculated weights, manufacturers, which are the model's second echelon are being ranked by the fuzzy-TOPSIS method. Since the model is of non-deterministic polynomial-time hardness (np-hard), due to its complexity, two different meta-heuristic algorithms-multi-objective particle swarm optimization (MOPSO) and non-dominated sorting genetic algorithm II (NSGA-II)- are conducted. Finally, the outputs of these algorithms are compared from the indices of quality, dispersion, and uniformity. The results illustrate that the production cost is of the highest rating among the most critical NPD criteria. The performance comparison of both aforementioned meta-heuristic algorithms reveals that MOPSO has the higher capability to explore the feasible region and solve the problem than NSGA-II. Whereas, from the aspect of run-time efficiency, NSGA-II has a faster execution time than MOPSO.

Keywords: Supply chain, Risk, NPD, MOPSO, NSGA-II.

\section{Introduction}

Companies have to perform more uniquely to survive and succeed in the current competitive market in today's constantly evolving technological world. In this context, product life cycle (PLC) is a variable that duly decreases as the competition, customer expectation, fluctuation of market share, and globalization increase (Bouncken et al., 2018), (Gmelin \& Seuring, 2014). Therefore, organizations cannot plan for long time horizons anymore and they should create the potentiality for regular innovations to remain competitive at all times (Jafarian \& Bashiri, 2014), (Brandenburg, 2015). To do so, NPD, which generally is the ability to design, manufacture and deliver new products to customers, plays an imperative role, for the reason that successful implementation of each NPD project could lead to the winning of challenge with opponents to possess the market share, enhancement of market response and finally growth in total revenue (Tang et al., 2009). In addition to the value mentioned above made for the manufacturer, NPD could also be valuable for distributors/agents and consumers. Boeing 787 dream-liner, as a successful example of an NPD project, had been launched due to the lost market proportion and intense competition with Airbus, made essential values for both the airlines as distributer centers (DCs) and passengers as consumers.

Table 1. Summary of NPD

\begin{tabular}{|l|l|l|l|}
\hline Dimension & Types & Description & References \\
\hline \multirow{3}{*}{ Phases } & Pre-Launch & $\begin{array}{l}\text { The time in which the market has not yet formed and the } \\
\text { uncertainty is rather high. Besides, the assessment of the } \\
\text { technical, market, business, and financial take place to be } \\
\text { more ready to face the critical situation of development time. }\end{array}$ & $\begin{array}{l}\text { (Cooper, } \\
\text { (Bouncken et } \\
\text { al., 2018) }\end{array}$ \\
\hline
\end{tabular}




\begin{tabular}{|c|c|c|c|}
\hline & Launch & $\begin{array}{l}\text { The market is formed, tensions and uncertainties are rather } \\
\text { low and commercialization takes place at this step. }\end{array}$ & \\
\hline \multirow{2}{*}{$\begin{array}{l}\text { Development } \\
\text { Types }\end{array}$} & Incremental & $\begin{array}{l}\text { There is no new product to be launched and merely the old } \\
\text { product gets developed. As an example, A version of a car } \\
\text { enhances in terms of appearance, technical, etc. from the } \\
\text { version of } 2015 \text { to } 2016 \text {. }\end{array}$ & \multirow{2}{*}{$\begin{array}{l}\text { (Bouncken et } \\
\text { al., 2018) }\end{array}$} \\
\hline & Radical & $\begin{array}{l}\text { New product launches which have considerable difference } \\
\text { with the old version, however, the degree of risk in this type } \\
\text { is rather high. }\end{array}$ & \\
\hline \multirow{2}{*}{$\begin{array}{l}\text { Launch } \\
\text { Types }\end{array}$} & $\begin{array}{l}\text { New products } \\
\text { launch - Old } \\
\text { products } \\
\text { phase-out }\end{array}$ & $\begin{array}{l}\text { Corporations only focus on the introduction of one product } \\
\text { to the market, since the demand for the old version has } \\
\text { expired. }\end{array}$ & \multirow{2}{*}{$\begin{array}{l}\text { (Jafarian \& } \\
\text { Bashiri, 2014) }\end{array}$} \\
\hline & $\begin{array}{l}\text { New products } \\
\text { launch along } \\
\text { with the old } \\
\text { products }\end{array}$ & $\begin{array}{l}\text { The demand for the old version remained potential and firms } \\
\text { should produce and supply both versions in parallel until the } \\
\text { demand of the previous version expires. }\end{array}$ & \\
\hline Process & \multicolumn{2}{|c|}{$\begin{array}{l}\text { Planning - Concept development/Idea generation - Business analysis } \\
\text { Detail design - Testing, prototyping, and validation - production - Introduction } \\
\text { to the market and commercialization - Result monitoring }\end{array}$} & $\begin{array}{l}\text { (Chauhan et } \\
\text { al., 2017), } \\
\text { (Markham \& } \\
\text { Lee, 2013) }\end{array}$ \\
\hline
\end{tabular}

(Tang et al, 2009) scrutinized the features of this development and categorized and outlined the values which Boeing made for both airlines and passengers. Table 1 summarizes the NPD introduction and outlines its phases, development types, launch types, and process.

\subsection{Success factors of NPD}

As stated before successful implementation of NPD schemes is of high importance. Therefore, there is a need to be highly informed about the main successful NPD factors. Successful here means the achievement of target development and on-time delivery (Chauhan et al., 2017). A Myriad of previous studies devoted their research on methods to address this issue. (Cooper et al, 2019) gathered 20 of the most critical aspects required to succeed in the development projects, some important of which are: uniqueness of the newly launched product, accurate assessment, planning and to be fact-based in the pre-development stage, prototyping, and testing by the presence of customers, consequently getting feedback and duly developing the old version of products. Besides, it stated that demand and financial resources are advised to be available before development. (Jafarian et al., 2014) outlined the importance of supplier integration and involvement as a successful NPD factor to contribute to the reduction of 
development lead time and prices; moreover, the dynamic configuration of the supply chain which changes per any transformation in products is claimed as another prospering root of NPD projects. (Hilletofth et al., 2018) revealed 4 categories of success factors in development projects which act as a bridge between NPD and supply chain management (SCM) context. These characteristics include market, strategy, product, and process. As an example, the development of new and innovative products in accordance with consumer preferences which is the sub-category of product characteristics is directly related to the innovation context of supply chain management concepts. On the one hand, (Markham \& Lee, 2013) added the role of management involvement and support as a relief to the process of NPD, and on the other hand, (Chang and Taylor, 2016) emphasized the role of customer engagement as a major source of knowledge in the process of NPD. While it might be true that relying solely on the customer's advice as a source of knowledge could not be authentic in all cases and there is a need to identify when and how to benefit from this valuable source, nevertheless, the NPD stages of ideation, development, and launch could highly get assist from the contribution of business customers and consumers. Technical advice, as an instance, is a solution-related knowledge that is provided by business customers, and it leads the manufacturers to be aware of preferences in the development stage of NPD. Besides, in the prototype testing, customers regularly have been invited to test the trial versions, which eventually could lead to the appraisal of the market and the launch of new products. Finally, the results disclosed the fact that customer engagement is more effective in low-tech industries, emerged countries, and small firms rather than high-tech industries, developed countries, and large firms.

\subsection{Roles of collaboration, coopetition (collaboration and competition), and knowledge sharing in NPD}

Collaboration, coopetition, and knowledge sharing are other dimensions that expedite the process of NPD. Collaboration is the interaction between supply chain entities that have mutual concerns to share their potential resources to ultimately achieve a viable solution (Yan \& Dooley, 2014). This is like a culture that is established for long-term cooperation between firms, and in this case, partners communicate openly and share the knowledge without any constraints, which leads to higher visibility and lower uncertainty (Dehdar et al., 2018). This collaboration is highlighted in the interaction between buyer and supplier.

That is to say; the buyer needs the supplier's resources such as innovative technologies, manufacturing technologies, and consequently, the supplier renders the specifications, new design recommendation and new technology flow to the firm, as well as the supplier, needs the buyers for market knowledge, product architecture information, project management capability, assembly coordination expertise, which in other words is supplier development activity to help and upgrade the systems and technologies of the supplier. Therefore, both parties rely on each other regarding the financial, human, and physical resources to share and handle the risks in NPD projects (Lawson et al., 2015), (Yan \& Dooley, 2014). Coopetition, however, which is the other strategy for the success of NPD is introduced as collaboration and competition spontaneously between competitors for a specific target (Bouncken et al., 2018) analyzed the operation of coopetition in the NPD process and realized that coopetition is only useful in the following order: 1) pre-launch incremental innovation, 2) launch phase incremental innovation, and 3) launch phase radical innovation. So coopetition in radical innovation in the phase of pre-launch is not 
positive and can even be destructive. Finally, knowledge sharing which is a key to be competitive in today's tough market emerges as an essential support to enhance the speed of introducing a product to market. (Gao and Bernard, 2018) sheds light on the importance of knowledge sharing as the most critical issue of knowledge management concept regarding the success of NPD projects. Utilizing knowledge management properly in this paper is defined as the main contribution to boosting efficiency, quality, and the speed of new product introduction to consumers.

\subsection{Role of risk management in NPD}

In this paper, the risk management (RM) approach is integrated with NPD concepts since utilizing RM properly to efficiently identify, evaluate and mitigate the risks that could ensure a successful NPD and prevent this process from delays in delivery of the new product (Chaudhuri et al., 2013), (Chauhan et al., 2017). Uncertainty is one of the widely-held risk categories in the process of NPD. Cost variation, customer demand fluctuation, processing time, transportation, material shortage, capacity expansion costs, lead time, social objectives, contracting with new suppliers, lack of knowledge about supplier performance, uniqueness of product design, the novelty of material used, and complexity of new product manufacturing process are the most outlined uncertainties throughout the launch of a new product (Chaudhuri et al., 2013), (Pasandideh et al., 2015), (Felfel et al., 2016). (Chauhan et al., 2017) introduced 3 main steps of implementing RM in NPD projects: 1) risk identification which is mainly done by extracting risk factors, doing surveys with experts, and utilizing interpretative structural modeling. 2) risk evaluation which is mainly done by assessment for the severity of risk factors, and 3) risk mitigation which regards the selection and implementation of the action plans. Supply chain risk management (SCRM) is a critical point to establishing an anti-risk system to prevent any changes in the normal material flow of supply chains by identifying, assessing, mitigating, and monitoring the disruptions to prevent any negative impact on the supply chain (Aqlan \& Lam, 2016). Being aware of the strategies to confront the risks involved in each industry is of paramount importance to make the supply chain resilient (the state of being able to return to its normal behavior after risk occurrence) and contribute to the NPD projects to be implemented on time.

Changing the structure of the supply chain to outsource more and to collaborate with tier-1 suppliers rather than with multiple suppliers, excess inventory, flexibility, insurance, risk-sharing contracts, and risk information-sharing mechanism are seem to be mostly used in reducing the risks in NPD projects (Tang et al., 2009), (Aqlan \& Lam, 2016), (Dehdar et al., 2018). (Tang et al., 2009) explored the risks that occurred after the launch of the Boeing 787 dream liner and introduced the risk mitigation strategies which Boeing exploited to confront them; these strategies encompass a substantial reform in the supply chain structure and collaborate merely with tier-1 suppliers instead of multiple suppliers to reduce the lead time, signing risk-sharing contracts with main suppliers, which subjected the payment to each supplier after successful launch and delivery of each aircraft, and so on. (Dehdar et al., 2018) extracted most of the risks involved in the automotive supply chain and explored the causes which lead to each risk, and finally proposed mitigation strategies to mitigate the risks.

\subsection{Supply chain mathematical optimization}

Considering the most relevant researches to this article in terms of mathematical aspects, (Javanshir et al., 2012) proposed a multi-level supply chain model and formulated it by mixed integer programming and solved it with both 
MOPSO and NSGA-II algorithms. The results were somehow similar to our research which shows that MOPSO was able to generate more Pareto solutions, and in terms of quality index, NSGA-II had a better function. (Chen et al., 2017) proposed a multi-objective closed-loop supply chain model to optimize total cost and $\mathrm{CO}_{2}$ emissions in the solar cell industry and employed the MOPSO algorithm to search the near-optimal solutions for the model. The result culminated in effective solutions to reach this aim, such as factory location options, capacity expansion, technology selection, and so on. Unlike our article which compares MOPSO with NSGA-II, (Fahimnia et al., 2018) compared the output of NSGA-II with Simulated annealing (SA) and Cross-Entropy (CE) algorithm for a green non-linear supply chain model and found that the CE algorithm has a better function in computation time and quality index, while SA produces a better result in the limitation of time, so these two methods are proposed as a better alternative for NSGA-II. (Hasanzadeh and Seifbarghy, 2018) compared the performance of NSGA-II with variable neighborhood search (VNS) method in solving a multi-objective optimization model, and the results showed that NSGA-II generates solutions with better quality, whereas VNS generates solutions with higher speed.

\subsection{Research questions}

In this paper, the above-mentioned elaborated topics are integrated to minimize costs, lead-time, and risks of a supply chain when new product launches and risks emerge as a result of NPD. In this procedure, some persuasive answers are supposed to be gathered for the following question:

1) What are the main criteria that lead the manufacturers of the Iranian UPVC profile industry to develop new products?

2) What are the risks, reasons, and mitigation strategies after NPD occurrence in the Iranian UPVC profile industry?

3) How costs, lead-time, and risks after the occurrence of NPD could be minimized in the Iranian UPVC profile industry?

4) Which meta-heuristic approach has a better performance in optimizing the supply chain of the Iranian UPVC profile industry?

\section{Methodology and case study}

In this paper, after a review process of relevant previous studies, primarily, the range of problem and the case study is identified, then, a multi-objective optimization model is proposed in a way which costs, lead time, and risks are minimized, and at the same time, NPD aspects are involved in the objective function of this model. The data to validate the model are extracted from the Iranian un-plasticized polyvinyl chloride (UPVC) profile industry as a downstream industry of petrochemical companies. The competitors in this industry compete so much to launch new series of profiles on regular basis to grasp other manufacturer's customer attention. This industry's supply chain comprises 4 echelons containing five major suppliers, six core manufacturers, an unlimited number of distributors/sales agents all over the country, and an unlimited number of consumers who are typical people inside or outside the country. Manufacturers, on the one hand, are competing on developing new series of products which consist of more inner chambers to enhance the resistance of windows and doors toward energy loss, entry of noises 
and any fractures; And because of the recent financial crisis, on the other hand, they simultaneously are striving to produce economic grades of profiles which the thickness of inner chambers of the profile are rather less to reduce the costs of production and ultimately decrease the prices and enhance competitiveness.

However, this industry is inundated with various types of risks, the most important of which are presented in this paper to be applied in the model and finally minimized. On average, eight products are manufactured in this industry. The planning period for our problem in this industry is considered to be twelve months. There is on average of 3600 tons demand/year for the total 8 products. Transportation costs from suppliers to manufacturers are on average 7500. This research will introduce a new product, the new series of UPVC profiles by the economic design, which is different from the aspects of weight, technical specification, and formulation compared to the previous series. This incremental development is done to cover a wide range of different demands in the market, which is now more oriented to lower costs due to the recent financial fluctuation inside the country. Elimination of extra inner walls of the profile, reduction of interior wall thickness, and simultaneous change in product formulation by reducing the dosage of more expensive raw materials and increasing the dosage of cheaper raw materials in the formulation by observing standard tolerance is the procedure of developing this new product.

In the following, in addition to the introduction of the most important NPD criteria, which are gathered by questionnaire method, these criteria are weighted by AHP. Based on the identified weights, manufacturers are prioritized through fuzzy-TOPSIS, which forms one of the most critical variables of the mathematical model $\left(\mathrm{w}_{\mathrm{j}}\right)$. Besides, risks and mitigation strategies extracted by an interview with experts are identified, which form the set of "q" in the proposed model. The complexity of the model made us employ meta-heuristic algorithms based on Pareto archives, and to assess the performance of algorithms, some test sample issues are solved through MOPSO. Finally, the results are compared with the outputs of the NSGA-II algorithm.

\section{Mathematical Optimization Model}

The case study's supply chain contains 4 echelons, and the model is assumed to be multi-period and multi-product. The capacity of the facilities is limited, and the number of facilities is not determined in advance. Suppliers and manufacturers can meet all potential demands. Maintenance costs are regarded to the inventory at the end of the planning period. The inventory is assumed to be available over the considered period, so there is no shortage of material for the production centers. Transportation costs are deemed to be a sub-category of purchasing costs. Tables 2 to 4 illustrate indices, parameters, and variables of the model, respectively.

Table 2-4. Model Indices

\begin{tabular}{|l|l|l|l|}
\hline Indices & Description & Indices & Description \\
\hline I & Set of suppliers & S & Set of products \\
\hline J & Set of manufacturers & q & Set of risk mitigation strategies \\
\hline K & Set of distributer centers (DCs) & T & Time periods \\
\hline L & Set of consumers & & \\
\hline
\end{tabular}


Asian Journal of Basic Science \& Research

Volume 3, Issue 3, Pages 65-92, July-September 2021

\begin{tabular}{|c|c|c|c|}
\hline Parameters & Description & Parameters & Description \\
\hline$c_{i j}^{s}$ & $\begin{array}{l}\text { Transportation costs of raw material } \\
\text { related to the product s from supplier i } \\
\text { to manufacturer } \mathrm{j}\end{array}$ & $C V A R D_{k q s t}$ & $\begin{array}{l}\text { Costs of employing strategy q to } \\
\text { mitigate the risk of late delivery of } \\
\text { product s by DC } \mathrm{k} \text { in period } \mathrm{t}\end{array}$ \\
\hline$c_{j k}^{s}$ & $\begin{array}{l}\text { Transportation costs of the product } \mathrm{s} \\
\text { from manufacturer } \mathrm{j} \text { to } \mathrm{DC} \mathrm{k}\end{array}$ & $C V A R Q_{i q s t}$ & $\begin{array}{l}\text { Costs of employing strategy q to } \\
\text { mitigate the risk of raw material of } \\
\text { product } S \text { to be damaged by } \\
\text { supplier i in period } t\end{array}$ \\
\hline$c q_{j k}^{s}$ & $\begin{array}{l}\text { Transportation costs of the product s } \\
\text { from manufacturer's warehouse } \mathrm{j} \text { to } \\
\text { DC k }\end{array}$ & $C V A R Q_{k q s t}$ & $\begin{array}{l}\text { Costs of employing strategy } q \text { to } \\
\text { mitigate the risk of product } S \text { being } \\
\text { damaged by DC } k \text { in period } t\end{array}$ \\
\hline$c_{k l}^{s}$ & $\begin{array}{l}\text { Transportation costs of the product } \mathrm{s} \\
\text { from DC } \mathrm{k} \text { to consumer } 1\end{array}$ & $C V A R N D_{j q t}$ & $\begin{array}{l}\text { Costs of employing strategy q to } \\
\text { mitigate risks of new product } \\
\text { development by manufacturer } \mathrm{j} \text { in } \\
\text { period } \mathrm{t}\end{array}$ \\
\hline$c d_{l s}$ & $\begin{array}{l}\text { Cost derived from lack of } \\
\text { responsiveness to consumer } 1 \text { per each } \\
\text { product s }\end{array}$ & $w_{j}$ & $\begin{array}{l}\text { Weight or priority of manufacturer } \\
\text { j based on NPD criteria }\end{array}$ \\
\hline$c q_{k l}^{s}$ & $\begin{array}{l}\text { Transportation costs of the product s } \\
\text { from DC's warehouse k to consumer } 1\end{array}$ & $C V A R D_{\text {iqst }}$ & $\begin{array}{l}\text { Costs of employing strategy q to } \\
\text { mitigate the risk of late delivery of } \\
\text { raw material related to product s } \\
\text { by supplier i in period } t\end{array}$ \\
\hline$c q_{j j}^{s}$ & $\begin{array}{l}\text { Transportation costs of the product } s \\
\text { from manufacturer } j \text { to its warehouse }\end{array}$ & $\operatorname{cost}_{j s}$ & $\begin{array}{l}\text { Costs of design and development } \\
\text { of new product s in manufacturer } \\
\text { site i }\end{array}$ \\
\hline$c q_{k k}^{s}$ & $\begin{array}{l}\text { Transportation costs of the product s } \\
\text { from DC } k \text { to its warehouse }\end{array}$ & $C R_{i s t}$ & $\begin{array}{l}\text { Costs of returning damaged raw } \\
\text { material of product } \mathrm{s} \text { to supplier } \mathrm{i} \\
\text { in period } \mathrm{t}\end{array}$ \\
\hline$R O_{s t}$ & $\begin{array}{l}\text { Maximum allowed quantity of product } \\
\text { s which needed to be returned in period } \\
t\end{array}$ & $d_{k l}$ & Distance from DC $\mathrm{k}$ to consumer 1 \\
\hline$d_{i j}$ & $\begin{array}{l}\text { Distance from the supplier I to } \\
\text { manufacturer } \mathrm{j}\end{array}$ & $d k_{k l}$ & $\begin{array}{l}\text { Distance from the warehouse of } \\
\text { DC k to consumer l }\end{array}$ \\
\hline
\end{tabular}


Asian Journal of Basic Science \& Research

Volume 3, Issue 3, Pages 65-92, July-September 2021

\begin{tabular}{|c|c|c|c|}
\hline$d_{j k}$ & Distance from manufacturer $\mathrm{j}$ to $\mathrm{DC} \mathrm{k}$ & $d j_{j}$ & $\begin{array}{l}\text { Distance from manufacturer } j \text { to its } \\
\text { warehouse }\end{array}$ \\
\hline$d j_{j k}$ & $\begin{array}{l}\text { Distance from the warehouse of } \\
\text { manufacturer } \mathrm{j} \text { to DC } \mathrm{k}\end{array}$ & $d k_{k}$ & $\begin{array}{l}\text { Distance from DC k to its } \\
\text { warehouse }\end{array}$ \\
\hline $\boldsymbol{B}$ & Total available budget to mitigate risks & $V A R D_{i s t}$ & $\begin{array}{l}\text { The risk level of late delivery of } \\
\text { raw material related to product s } \\
\text { by the supplier I in period t }\end{array}$ \\
\hline$V A R D_{k s t}$ & $\begin{array}{l}\text { The risk level of late delivery of } \\
\text { product } \mathrm{s} \text { by DC } \mathrm{k} \text { in period } \mathrm{t}\end{array}$ & $V A R Q_{i s t}$ & $\begin{array}{l}\text { The risk level of damaged raw } \\
\text { material for product } \mathrm{s} \text { by the } \\
\text { supplier I in period } \mathrm{t}\end{array}$ \\
\hline$V A R N D_{j t}$ & $\begin{array}{l}\text { The risk level of new product } \\
\text { development by manufacturer } \mathrm{j} \text { in } \\
\text { period } \mathrm{t}\end{array}$ & $F_{\text {ist }}$ & $\begin{array}{l}\text { Flexibility level of supplier I to } \\
\text { supply raw material of product s in } \\
\text { period } t\end{array}$ \\
\hline FO & $\begin{array}{l}\text { considered flexibility range for } \\
\text { suppliers }\end{array}$ & $f_{k}$ & $\begin{array}{l}\text { Costs for constructing DC in point } \\
k\end{array}$ \\
\hline$h_{j}^{s}$ & $\begin{array}{l}\text { Maintenance cost of product } \mathrm{s} \text { in } \\
\text { manufacturer's warehouse } \mathrm{j}\end{array}$ & $\boldsymbol{h}_{k}^{s}$ & $\begin{array}{l}\text { Maintenance cost of product s in } \\
\text { DC's warehouse } \mathrm{k}\end{array}$ \\
\hline $\boldsymbol{O}_{\text {ist }}$ & $\begin{array}{l}\text { Order cost of the product s to supplier I } \\
\text { in period } t\end{array}$ & $R_{\text {ist }}$ & $\begin{array}{l}\text { Level of the returned product } \mathrm{s} \text { to } \\
\text { supplier I in period } t\end{array}$ \\
\hline$L D C_{i s t}$ & $\begin{array}{l}\text { The average lead time of preparing raw } \\
\text { material of product s by supplier i in } \\
\text { period } t\end{array}$ & $t d_{l s t}$ & $\begin{array}{l}\text { Average lead time to prepare } \\
\text { product } \mathrm{s} \text { for final consumer } 1 \text { in } \\
\text { period } \mathrm{t}\end{array}$ \\
\hline$d_{l t}^{s}$ & $\begin{array}{l}\text { Demand level of the product } \mathrm{s} \text { by } \\
\text { consumer } 1 \text { in period } \mathrm{t}\end{array}$ & $c a_{i}$ & The supply capacity of supplier i \\
\hline$c a_{j}$ & The supply capacity of manufacturer $j$ & $c a_{k}$ & The supply capacity of DC k \\
\hline$c a j_{j}$ & Warehouse capacity of manufacturer $\mathrm{j}$ & $\operatorname{cak}_{k}$ & Warehouse capacity of DC k \\
\hline
\end{tabular}

\begin{tabular}{|c|l|l|l|}
\hline Variables & Description & Variables & Description \\
\hline$x_{i j t}^{s}$ & $\begin{array}{l}\text { Level of raw material flow for } \\
\text { manufacturing product s from supplier i } \\
\text { to manufacturer j in period t }\end{array}$ & $\boldsymbol{x}_{\boldsymbol{j} \boldsymbol{s} t}^{\boldsymbol{s}}$ & $\begin{array}{l}\text { Level of product s flow from } \\
\text { manufacturer j to DC k in period t }\end{array}$ \\
\hline
\end{tabular}


Asian Journal of Basic Science \& Research

Volume 3, Issue 3, Pages 65-92, July-September 2021

\begin{tabular}{|c|c|c|c|}
\hline$x_{k l t}^{s}$ & $\begin{array}{l}\text { Level of product } \mathrm{s} \text { flow from } \mathrm{DC} \mathrm{k} \text { to } \\
\text { consumer } 1 \text { in period } \mathrm{t}\end{array}$ & $Q_{k k t}^{s}$ & $\begin{array}{l}\text { Level of the product } \mathrm{s} \text { from } \mathrm{DC} \mathrm{k} \\
\text { to its warehouse in period } \mathrm{t}\end{array}$ \\
\hline$Q_{k l t}^{S}$ & $\begin{array}{l}\text { Level of product s flow from DC's } \\
\text { warehouse to consumer } 1 \text { in period t }\end{array}$ & $Q_{j k t}^{S}$ & $\begin{array}{l}\text { Level of product } \mathrm{s} \text { flow from } \\
\text { manufacturer's warehouse to DC } \mathrm{k} \\
\text { in period } \mathrm{t}\end{array}$ \\
\hline$Q_{j j t}^{S}$ & $\begin{array}{l}\text { Level of product s flow from } \\
\text { manufacturer's warehouse to its } \\
\text { warehouse in period } t\end{array}$ & $U_{j t}^{S}$ & $\begin{array}{l}\text { Level of product s stock in } \\
\text { manufacturer's warehouse in } \\
\text { period t }\end{array}$ \\
\hline$U_{k t}^{s}$ & $\begin{array}{l}\text { Level of product s stock in DC's } \\
\text { warehouse in period } t\end{array}$ & $x_{i q s t}$ & $\begin{array}{l}\text { If strategy q is employed to } \\
\text { mitigate the risk of "late delivery } \\
\text { of raw material for product s by } \\
\text { supplier" } 1 \text { and if not } 0\end{array}$ \\
\hline$x Q_{i q s t}$ & $\begin{array}{l}\text { If strategy q is employed to mitigate the } \\
\text { risk of "damaged raw material for } \\
\text { product s by supplier I" } 1 \text { and if not } 0\end{array}$ & $x_{k q s t}$ & $\begin{array}{l}\text { If strategy } q \text { is employed to } \\
\text { mitigate the risk of "late delivery } \\
\text { of product } \mathrm{s} \text { by DC k" } 1 \text { and if not } \\
0\end{array}$ \\
\hline$x Q_{k q s t}$ & $\begin{array}{l}\text { If strategy q is employed to mitigate the } \\
\text { risk of "delivery of damaged product s } \\
\text { by DC k" } 1 \text { and if not } 0\end{array}$ & $x D_{j q t}$ & $\begin{array}{l}\text { If strategy q is employed to } \\
\text { mitigate the risk of "NPD by } \\
\text { manufacturer } \mathrm{j} " 1 \text { and if not } 0\end{array}$ \\
\hline$x F_{i q t}$ & $\begin{array}{l}\text { If strategy q is employed to mitigate the } \\
\text { risk of "Demand fluctuation by supplier } \\
\text { I" } 1 \text { and if not } 0\end{array}$ & $q_{l t}^{s}$ & $\begin{array}{l}\text { Level of unsatisfied demand of } \\
\text { consumer } 1 \text { for product } \mathrm{s} \text { in period } \mathrm{t}\end{array}$ \\
\hline $\mathbf{y}_{\boldsymbol{k}}$ & If DC constructs in point $\mathrm{k} 1$ and if not 0 & & \\
\hline
\end{tabular}

In the following a multi-objective mixed-integer non-linear programming is proposed:

$$
\begin{aligned}
& \operatorname{Min} \mathbf{z 1}=\quad \sum f_{k} y_{k}+\sum_{t \in T}\left(\sum_{s \in S} \sum_{i \in I} \sum_{j \in J} c_{i j}^{S} d_{i j} x_{i j t}^{S}+\sum_{s \in S} \sum_{j \in J}\left(1-w_{j}\right) \sum_{k \in K}\left(c_{j k}^{S} d_{j k} x_{j k t}^{s}+c q_{j k}^{S} d j_{j k} Q_{j k t}^{S}\right)\right. \\
& +\sum_{s \in S} \sum_{k \in K} \sum_{l \in L}\left(c_{k l}^{S} d_{k l} x_{k l t}^{S}+c q_{k l}^{S} d k_{k l} Q_{k l t}^{S}\right)+\sum_{s \in S} \sum_{j \in J} c q_{j j}^{S} d j_{j} Q_{j j t}^{S}+\sum_{s \in S} \sum_{k \in K} c q_{k k}^{S} d k_{k} Q_{k k t}^{S} \\
& +\sum_{t \in T}\left(\sum_{s \in S} \sum_{j \in J} h_{j}^{S} U_{j t}^{S}+\sum_{s \in S} \sum_{k \in K} h_{k}^{S} U_{k t}^{S}\right)+\sum_{i \in I} \sum_{t \in T} \sum_{s \in S} o_{i s t} \sum_{j \in J} x_{i j t}^{S}+\sum_{i \in I} \sum_{t \in T} \sum_{s \in S} C R_{i s t} R_{i s t} \sum_{j \in J} x_{i j t}^{S} \\
& +\sum_{t} \sum_{l} \sum_{s} c d_{l s} q_{l t}^{s}+\sum_{q}\left(\sum_{t=1}^{T} \sum_{s=1}^{S} \sum_{i=1}^{I} C V A R D_{i q s t} x_{i q s t}\right.
\end{aligned}
$$




$$
\begin{aligned}
& +\sum_{t=1}^{T} \sum_{s=1}^{S} \sum_{k=1}^{K} C V A R D_{k q s t} x_{k q s t}+\sum_{t=1}^{T} \sum_{s=1}^{S} \sum_{i=1}^{I} C V A R Q_{i q s t} x Q_{i q s t} \\
& +\sum_{t=1}^{T} \sum_{s=1}^{S} \sum_{k=1}^{K} C V A R Q_{k q s t} x Q_{k q s t}+\sum_{t=1}^{T} \sum_{j=1}^{J} C V A R N D_{j q t} x D_{j q t} \\
& \left.+\sum_{s \in S} \sum_{j \in J} \operatorname{cost}_{j s}\left(Q_{j j t}^{S}+\sum_{k \in K} x_{j k t}^{S}\right)\right) \\
& \min \mathbf{z 2}=\sum_{i \in I} \sum_{t \in T} \sum_{s \in S} L D C_{i s t} \sum_{j \in J} x_{i j t}^{s}+\sum_{s \in S} \sum_{t \in T} \sum_{l \in L} t d_{l s t} \sum_{k \in K}\left(x_{k l t}^{S}+Q_{k l t}^{S}\right) \\
& \min \mathbf{z} 3=\sum_{t=1}^{T} \sum_{s=1}^{S} \sum_{i=1}^{I} V A R D_{i s t}\left(\sum_{j=1}^{J} x_{i j t}^{S}\right) \\
& +\sum_{t=1}^{T} \sum_{s=1}^{S} \sum_{k=1}^{K} V A R D_{k s t}\left(\sum_{l=1}^{L} x_{k l t}^{S}\right)+\sum_{t=1}^{T} \sum_{s=1}^{S} \sum_{i=1}^{I} V A R Q_{i s t}\left(\sum_{j=1}^{J} x_{i j t}^{S}\right) \\
& +\sum_{t=1}^{T} \sum_{s=1}^{S} \sum_{k=1}^{K} V A R Q_{k s t}\left(\sum_{l=1}^{L} x_{k l t}^{S}\right)+\sum_{t=1}^{T} \sum_{s=1}^{S} \sum_{j=1}^{J} V A R N D_{j t}\left(Q_{j j t}^{S}\right. \\
& \left.+\sum_{k=1}^{K} x_{j k t}^{s}\right)
\end{aligned}
$$

\section{Subject to:}

$\sum_{k}\left(x_{k l t}^{S}+Q_{k l t}^{S}\right)+q_{l t}^{S}=d_{l t}^{S} \forall l, t, s$

$\sum_{j}\left(x_{j k t}^{S}+Q_{j k t}^{S}\right)=\sum_{l} x_{k l t}^{s}+Q_{k k t}^{S} \quad \forall k, s, t$

$\sum_{i} x_{i j t}^{S}=\sum_{k} x_{j k t}^{S}+Q_{j j t}^{s} \quad \forall j, s, t$

$U_{j t}^{s}=Q_{j j t}^{s}+U_{j t-1}^{s}-\sum_{k} Q_{j k t}^{s} \quad \forall j, s, t$

$U_{j t}^{S}=Q_{j j t}^{S}-\sum_{k} Q_{j k t}^{S} \quad \forall j, s$

$U_{k t}^{S}=Q_{k k t}^{S}+U_{k t-1}^{S}-\sum_{k} Q_{k l t}^{S} \quad \forall k, s, t$

$U_{k t}^{S}=Q_{k k t}^{S}-\sum_{k} Q_{k l t}^{S} \quad \forall k, s$

$\sum_{k} Q_{j k t}^{S} \leq Q_{j j t}^{S} \quad \forall j, s, t$ 
$\sum_{l} Q_{k l t}^{S} \leq Q_{k k t}^{S} \quad \forall k, s, t$

$\sum_{\mathrm{s}} \sum_{\mathrm{j}} \mathrm{x}_{\mathrm{ijt}}^{\mathrm{s}} \leq \mathrm{ca}_{\mathrm{i}} \quad \forall \mathrm{i}, \mathrm{t}$

$\sum_{s} \sum_{\mathrm{k}} \mathrm{X}_{\mathrm{jkt}}^{\mathrm{s}}+\sum_{\mathrm{s}} \mathrm{Q}_{\mathrm{jjt}}^{\mathrm{s}} \leq \mathrm{ca}_{\mathrm{j}} \quad \forall \mathrm{j}, \mathrm{t}$

$\sum_{\mathrm{s}} \sum_{\mathrm{l}} \mathrm{x}_{\mathrm{klt}}^{\mathrm{s}}+\sum_{\mathrm{s}} \mathrm{Q}_{\mathrm{kkt}}^{\mathrm{s}} \leq \mathrm{ca}_{\mathrm{k}} \mathrm{y}_{\mathrm{k}} \quad \forall \mathrm{k}, \mathrm{t}$

$\sum_{\mathrm{s}} \mathrm{U}_{\mathrm{jt}}^{\mathrm{s}} \leq \mathrm{caj}_{\mathrm{j}} \quad \forall \mathrm{j}, \mathrm{t}$

$\sum_{\mathrm{s}} \mathrm{U}_{\mathrm{kt}}^{\mathrm{s}} \leq \operatorname{cak}_{\mathrm{k}} \mathrm{y}_{\mathrm{k}} \quad \forall \mathrm{k}, \mathrm{t}$

$\sum_{\mathrm{k}} \mathrm{y}_{\mathrm{k}} \geq 1$

$\sum_{t \in T} \sum_{i \in I} R_{i s t} \sum_{i \in I} x_{i j t}^{s} \leq R O_{s t} \sum_{t \in T} \sum_{l \in L} d_{l t}^{s} \quad \forall s$

$F_{i s t} \sum_{j \in J} x_{i j t}^{s} \geq F_{j s t} \quad \forall i, s, t$

$\sum_{q}\left(\sum_{t=1}^{T} \sum_{s=1}^{S} \sum_{i=1}^{I} C V A R D_{i q s t} x_{i q s t}+\sum_{t=1}^{T} \sum_{s=1}^{S} \sum_{k=1}^{K} C V A R D_{k q s t} x_{k q s t}+\sum_{t=1}^{T} \sum_{s=1}^{S} \sum_{i=1}^{I} C V A R Q_{i q s t} x Q_{i q s t}\right.$

$\left.+\sum_{t=1}^{T} \sum_{s=1}^{S} \sum_{k=1}^{K} C V A R Q_{k q s t} x Q_{k q s t}+\sum_{t=1}^{T} \sum_{j=1}^{J} C V A R N D_{j q t} x D_{j q t}\right) \leq B$

$\mathrm{y}_{\mathrm{l}}, \mathrm{y}_{\mathrm{k}} \in\{0,1\} \forall \mathrm{l}, \mathrm{k}$

$\mathrm{x}, \mathrm{xQ}, \mathrm{xD}, \mathrm{Q}_{\mathrm{kkt}}^{\mathrm{s}}, \mathrm{Q}_{\mathrm{klt}}^{\mathrm{s}}, \mathrm{U}_{\mathrm{jt}}^{\mathrm{s}}, \mathrm{U}_{\mathrm{kt}}^{\mathrm{s}} \geq 0 \quad \forall \mathrm{i}, \mathrm{j}, \mathrm{k}, \mathrm{l}, \mathrm{s}, \mathrm{t}$

The objective function is shown in equation (1) minimizes total costs from the aspects of DC construction, design and development of new products, transportation, maintenance, order to suppliers, the return of defective products, failed orders or demands, and utilization of risk mitigation strategies. Equation (2) minimizes lead time from the aspects of raw material preparation by suppliers and final products preparation for consumers.

The objective function (3) minimizes risks of late delivery, damaged products in the chain of supply and NPD process. Constraint (4) calculates the level of failed orders or unsatisfied demand. Constraints (5) to (10) limit the flow in supply chain nodes. The constraints in inequality (11) and (12) guarantee that the outflow from the warehouse of manufacturers and DCs do not exceed the total inflow to their warehouse. The constraints in inequality (13) to (17) assure that, on the one hand, the flow of material circulates between the nodes in which a 
facility has been established in there, and on the other hand, the total flow in each node does not exceed its capacity. Constraint (18) states that a minimum of $1 \mathrm{DC}$ is established and is active in the supply chain. The constraint in inequality (19) specifies that the total quantity of returned material does not exceed the maximum allowed quantity. Constraint (20) refers to the level of supplier's flexibility, which needs to be more than considered level. The constraint inequality (21) guarantees that the costs of employing risk mitigation strategies do not exceed the total budget. Finally, constraints (22) and (23) are the rational and apparent limitations of the model variables.

\section{Data analysis and solution procedure}

\subsection{Data Analysis}

To validate the model, primarily, the required data from the industry of the case study are extracted. To do so, after studying the case study and presenting the NPD case in part 2 of this paper, the most important criteria to develop the new product in the Iranian UPVC profile industry have been extracted throughout the questionnaire method, then these criteria are weighted by the AHP method. Based on the identified weights, major manufacturers of this industry are prioritized by the fuzzy TOPSIS method, which culminates in the output of parameter $w_{j}$ of the proposed model. Besides, risks, causes, and risk mitigation strategies of this industry are gathered by interviews with experts. This will form the $q$ set of the proposed model. Other data of this industry are extracted by document mining and the summary of which is presented in the following.

\subsection{NPD most important criteria}

As stated above, the first step of the solution procedure of this research is to identify the most important criteria of our case study. These criteria are the most important reason why the manufacturers of this industry turn to the development of a new product. Similar to the procedure of Tang et al. [4] the situations of corporations in this industry before NPD are compared with after NPD. Table (5) clarifies this procedure.

Table 5. NPD criteria

\begin{tabular}{|l|l|l|}
\hline Criteria & Before NPD & After NPD \\
\hline Production costs & $\begin{array}{l}\text { Due to the high costs of raw } \\
\text { materials, sales prices were high } \\
\text { and profit margins were low }\end{array}$ & $\begin{array}{l}\text { Due to the reduction of } \\
\text { consuming expensive raw } \\
\text { dosage of cheap raw material, } \\
\text { sales price decline, and profit } \\
\text { margin }\end{array}$ \\
\hline Demand responsiveness & $\begin{array}{l}\text { Covering low level of market } \\
\text { demand because of higher prices }\end{array}$ & $\begin{array}{l}\text { Products are supplied in 2 grades } \\
\text { of normal and economical and } \\
\text { cover all economic levels of the } \\
\text { society }\end{array}$ \\
\hline
\end{tabular}


Asian Journal of Basic Science \& Research

Volume 3, Issue 3, Pages 65-92, July-September 2021

\begin{tabular}{|l|l|l|}
\hline \multirow{2}{*}{ Market competitiveness } & $\begin{array}{l}\text { Limitation in discount, shortage in } \\
\text { the product portfolio, the } \\
\text { orientation of customers to import } \\
\text { cheaper profiles from near } \\
\text { countries }\end{array}$ & $\begin{array}{l}\text { Increase in product diversity and } \\
\text { higher opportunity to gain } \\
\text { market share }\end{array}$ \\
\hline
\end{tabular}

Afterward, by employing the method of questionnaire to collect data from 9 experts of this industry, the NPD criteria are quantified and weighted through the AHP method. Primarily, the pair-wise comparisons of these criteria are illustrated in table (6).

Table 6. NPD criteria wise-comparison matrix

\begin{tabular}{|l|l|l|l|}
\hline Criteria & $\begin{array}{l}\text { Production } \\
\text { costs }\end{array}$ & $\begin{array}{l}\text { Demand } \\
\text { responsiveness }\end{array}$ & $\begin{array}{l}\text { Market } \\
\text { competitiveness }\end{array}$ \\
\hline Production costs & 1 & 4.556 & 4.778 \\
\hline $\begin{array}{l}\text { Demand } \\
\text { responsiveness }\end{array}$ & 0.234 & 1 & 1.444 \\
\hline $\begin{array}{l}\text { Market } \\
\text { competitiveness }\end{array}$ & 0.225 & 0.815 & 1 \\
\hline Total & 1.459 & 6.370 & 7.222 \\
\hline
\end{tabular}

After normalizing the previous table by dividing each value by the total column value and afterward calculating the priority vector or eigenvector through obtaining the mathematical average of all criteria and finally multiplying the primitive total value by the eigenvector value, the maximum eigenvalue is calculated in the table (7).

Table 7. Eigenvector value

\begin{tabular}{|l|l|}
\hline Dimensions & Eigenvector \\
\hline Production costs & 2.143 \\
\hline Demand responsiveness & 0.536 \\
\hline Market competitiveness & 0.436 \\
\hline Maximum eigenvalue $\left(\lambda_{\max }\right)$ & $2.143+0.536+0.436=\mathbf{3 . 1 1 5}$ \\
\hline
\end{tabular}


To check the matrix to be consistent, consistency ratio (CR) should be calculated and must be less than $10 \%$. To do so, the first consistency index (CI) is calculated by the following formula:

$C I=\frac{\lambda_{\max }-n}{n-1}$

( $\mathrm{n}$ is the number of evaluated criteria): $\mathbf{C I} \mathbf{=} \mathbf{0 . 0 5 7 5}$

$C R=\frac{C I}{R I}$

( $\mathrm{RI}$ is fixed and based on random consistency index, $\mathrm{RI}$ for $\mathrm{n}=3$ is 0.58 ): $\mathbf{C R = 0 . 9 9 1}$

Since CR is less than $10 \%$, the pair-wise comparison of NPD criteria is consistent and valid.

\subsection{Manufacturers ranking}

Based on the calculated weights of NPD criteria, in this part manufacturers of our case study's industry are ranked through fuzzy TOPSIS method, and criteria which weighted in the AHP procedure are used as sub-criteria. To do so, primarily a table has been arranged in which its columns include the criteria and its rows represent manufacturers. This table is provided to 9 experts of the industry and asked to value each manufacturer based on the importance of criteria from 1 to 5 . Then based on fuzzy numbers for linguistic values presented in table (8). (Chen and Huang, 44] the values are changed to fuzzy numbers, then based on the calculated average of rates the table is normalized and presented in table (9).

Table 8. Fuzzy numbers for the linguistic value

\begin{tabular}{|l|l|l|}
\hline number & Linguistic value & Fuzzy numbers \\
\hline 1 & Very Low & $(0,0,0.2)$ \\
\hline 2 & Low & $(0,0.2,0.4)$ \\
\hline 3 & Medium & $(0.3,0.5,0.7)$ \\
\hline 4 & High & $(0.6,0.8,1)$ \\
\hline 5 & Very High & $(0.8,1,1)$ \\
\hline
\end{tabular}

Table 9. Normalized fuzzy decision-making matrix

\begin{tabular}{|l|l|l|l|}
\hline Criteria & Production costs & $\begin{array}{l}\text { Demand } \\
\text { responsiveness }\end{array}$ & $\begin{array}{l}\text { Market } \\
\text { competitiveness }\end{array}$ \\
\hline Manufacturer 1 & $(0.6,0.8,1)$ & $(0.3,0.5,0.7)$ & $(0.6,0.8,1)$ \\
\hline Manufacturer 2 & $(0.6,0.8,1)$ & $(0.8,1,1)$ & $(0.6,0.8,1)$ \\
\hline Manufacturer 3 & $(0.3,0.5,0.7)$ & $(0.3,0.5,0.7)$ & $(0.6,0.8,1)$ \\
\hline
\end{tabular}




\begin{tabular}{|l|l|l|l|}
\hline Manufacturer 4 & $(0.6,0.8,1)$ & $(0.6,0.8,1)$ & $(0.6,0.8,1)$ \\
\hline Manufacturer 5 & $(0.3,0.5,0.7)$ & $(0.3,0.5,0.7)$ & $(0.6,0.8,1)$ \\
\hline Manufacturer 6 & $(0.3,0.5,0.7)$ & $(0.3,0.5,0.7)$ & $(0.6,0.8,1)$ \\
\hline
\end{tabular}

After computing fuzzy positive ideal solution (FPIS) which is shown by $A^{+}$and fuzzy negative ideal solution (FNIS) which is shown by $A^{-}$and calculating the distance of each alternative from $A^{+}$to $A^{-}$which are shown by $d^{*}$ and $d^{-}$, closeness coefficient $\left(C C_{i}\right)$ for each alternative is computed and each alternative has a higher $C C_{i}$ represents the best alternative and the summary is shown in table (9).

$$
\begin{aligned}
& A^{+}=\left(\tilde{\mathrm{v}}_{1}^{*}, \tilde{\mathrm{v}}_{2}^{*}, \tilde{\mathrm{v}}_{3}^{*}, \ldots, \tilde{\mathrm{v}}_{n}^{*}\right)=\left\{\max v_{i j} \mid(i=1,2, \ldots, m, j=1,2, \ldots, n)\right\} \\
& A^{-}=\left(\tilde{\mathrm{v}}_{1}^{-}, \tilde{\mathrm{v}}_{1}^{-}, \tilde{\mathrm{v}}_{1}^{-}, \ldots, \tilde{\mathrm{v}}_{1}^{-}\right)=\left\{\min v_{i j} \mid(i=1,2, \ldots, m, j=1,2, \ldots, n)\right\} \\
& d_{i}^{*}=\sum_{j=1}^{n} d\left(\widetilde{v}_{i j}, \widetilde{v}_{j}^{*}\right), \quad i=1, \ldots, m, \\
& d_{i}^{-}=\sum_{j=1}^{n} d\left(\tilde{v}_{i j}, \tilde{v}_{j}^{-}\right), \quad i=1, \ldots, m, \\
& C C_{i}=\frac{d_{i}^{-}}{d_{i}^{*}+d_{i}^{-}}, \quad A_{i}(i=1, \ldots, m)
\end{aligned}
$$

The following table identifies ranks of the manufacturers and forms the $w_{j}$ set of the proposed optimization model.

Table 10. Ranking of manufacturers with fuzzy TOPSIS

\begin{tabular}{|l|l|l|}
\hline Rank & \multicolumn{1}{|c|}{$C C_{i}$} & Manufacturers \\
\hline 1 & 0.62549 & Manufacturer 1 \\
\hline 2 & 0.61871 & Manufacturer 2 \\
\hline 3 & 0.60053 & Manufacturer 3 \\
\hline 4 & 0.53219 & Manufacturer 4 \\
\hline 5 & 0.47732 & Manufacturer 5 \\
\hline 6 & 0.35132 & Manufacturer 6 \\
\hline
\end{tabular}

\subsection{Risks, causes and mitigation strategies}

As stated before risks and mitigation strategies employed in the case study of this research are involved in the proposed optimization model. Table (11) renders the most important risks, causes, and mitigation strategies and form the $q$ set of the mathematical model. The structure of this table is similar to the table provided in the research of (Dehdar et al., 2018). The following data are gathered via interviews with top managers of case study's industry. 
Table 11. Risks, causes, and mitigation strategies

\begin{tabular}{|c|c|c|c|}
\hline Risks & Causes & & Mitigation strategies \\
\hline $\begin{array}{l}\text { Raw material } \\
\text { supply }\end{array}$ & 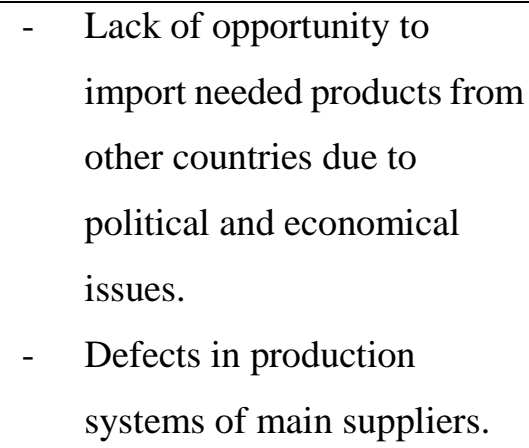 & - & $\begin{array}{l}\text { Localization and production } \\
\text { needed raw material inside the } \\
\text { country. } \\
\text { Purchase additional amount as } \\
\text { precautionary quantity in every } \\
\text { order point. } \\
\text { Purchase from multi suppliers. }\end{array}$ \\
\hline $\begin{array}{l}\text { Lead time } \\
\text { fluctuation }\end{array}$ & $\begin{array}{l}\text { - Lack of familiarity of } \\
\text { operators to produce new } \\
\text { products when NPD occurs. } \\
\text { - } \text { Issues in transportation } \\
\text { routes Such as heavy rain on } \\
\text { the way, vehicle breakdown, } \\
\text { etc. } \\
\text { - Production equipment } \\
\text { failure. }\end{array}$ & - & $\begin{array}{l}\text { Hiring experienced technical } \\
\text { personnel with higher education } \\
\text { and familiar with the PVC } \\
\text { industry to supervise production } \\
\text { operators. } \\
\text { Collaborate with several } \\
\text { dedicated and ready-to-use } \\
\text { drivers for transportation } \\
\text { Special attention to repairs and } \\
\text { maintenance of production } \\
\text { equipment. }\end{array}$ \\
\hline $\begin{array}{l}\text { Demand } \\
\text { fluctuation }\end{array}$ & 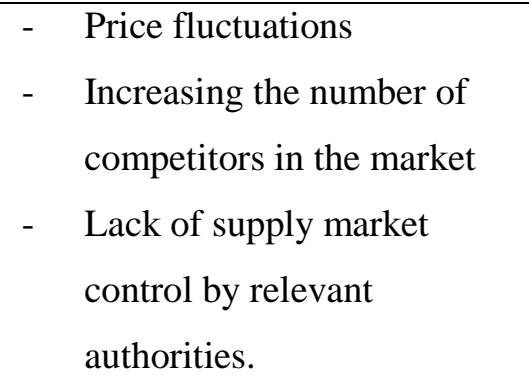 & - & $\begin{array}{l}\text { Eliminate brokers from the } \\
\text { market and control the pricing of } \\
\text { producers by government } \\
\text { regulators. }\end{array}$ \\
\hline
\end{tabular}

\subsection{Solution procedure}

Primarily, to integrate the objective functions of the proposed model, min-max goal programming, which integrates the objectives as composition and minimizes the maximum deviation from the goals, is utilized (Deb, 2001). Then, due to the complexity and the size of the model, employing evolutionary algorithms, the most important of which are particle swarm optimization (PSO) and genetic algorithm (GA) could efficiently lead the problems to the best solutions. In this paper, multi-objective functions are employed to deal with the 3 objective functions of the proposed model. To do so, some sample problems are solved by MOPSO and the outputs are compared with those solved by NSGA-II. The reasons why the MOPSO algorithm is selected as the main method to solve the problem are low computational cost, better performance, and easier implementation procedure. 


\subsubsection{Min-max goal programming}

Goal programming (GP) is a sub-category of multi-objective optimization field and integrates the conflicting objective functions of an optimization mathematical model, in a way in which a value is allocated for each function and deviation from the value are calculated and minimized (Huang et al., 2017). This is done by 3 main methods including weighted GP, lexicographic GP, and min-max GP. Min-max GP, which acts as a weighted GP in terms of consideration of weight factors. Unlike weighted GP, which minimizes the weighted sum of deviation, min-max GP minimizes the maximum deviation of each objective function from the target (Deb, 2001). To solve the proposed model of this paper, the objective functions are integrated using a non-linear programming model based on min-max GP as follows:

\section{Minimize $D$}

Subject to:

$\left(u_{i} n_{i}+v_{i} p_{i}\right) \leq \mathrm{D}$

$f_{i}+n_{i}-p_{i}=b_{i}$

$n_{i}, p_{i} \geq 0$

(D: maximum deviation from the objective, $u_{i}$ and $v_{i}$ : positive and negative deviation from the objective)

\subsubsection{MOPSO}

PSO, first proposed by Kennedy and Eberhart (1995), is a method based on population that can be in a form of ants, bees, birds, etc. The whole population constitutes potential solutions defined as a swarm and each individual amongst the swarm is defined as a particle. These particles search for the best solution of their own experience and the other particle's experience of the same swarm to find the best solution for the problem. Due to the limitation of PSO in solving multi-objective problems, Moore and Chapman (1999) introduced the MOPSO algorithm which deals with models of more than one objective, in which a set of solutions by Pareto optimal solution is determined.

\subsubsection{NSGA-II}

Another applicable algorithm to lead a multi-objective problem to Pareto optimal solution is NSGA-II, which was first introduced by Deb et al. (2002). This algorithm consists of generating a random population, evaluation of population by the evaluation process, ranking of the population by non-dominated sorting procedure, calculation of crowding distance by linear distance criterion, selection of new population by crossover and mutation operator, sorting population-based on ascending and descending order and finally as soon as the stop criteria will be met, a set of non-dominated Pareto optimal solution is obtained (Pasandideh et al. 2015).

\subsubsection{Structure and characteristics of MOPSO}

The overall designed structure for the MOPSO algorithm is as follows:

Generate $\mathrm{N}$ feasible solutions as initial population. 
Apply improvement procedure for generated particles.

Apply feasibility check procedure for improved particles.

Initialize $\mathrm{p}_{\mathrm{g}}$ and $\mathrm{p}_{\mathrm{i}}$.

Initialize the adaptive Pareto archive set so that it is empty

While a given maximal number of iterations is not achieved

Update particle by eq. (34)

Improve population of particles.

Apply feasibility check procedure.

Evaluate the updated particles to get the new $p_{i}$ and $p_{g}$

Update Pareto archive.

Select $N$ solutions with higher quality and higher diversity as the population for the next generation.

End while

\}

Return Pareto archive

\}

\subsubsection{Improvement procedure}

The improvement procedure in this paper is based on variable neighborhood search (VNS) (Roshanaei et al. 2009), which is as the following:

\{for each input solution $\mathrm{s}$

$\mathrm{K}=1$

While the stopping criterion is met do

$\mathrm{S} 1=$ Apply mutation type $\mathrm{k}$

$\mathrm{S}=$ Acceptance method $(\mathrm{S}, \mathrm{S} 1)$

If $s$ is improved then

$\mathrm{K}=1$

Else

$\mathrm{K}=\mathrm{k}+1$

If $\mathrm{k}=3$ then

$\mathrm{K}=1$

End if

End while\}

As can be seen in the structure above, after applying the variable neighborhood structure to the answer, the acceptance procedure is applied to the resulting answer and the previous answer, and one of the two answers is 
selected as the next VNS iteration answer. The acceptance procedure operates in such a way that it determines and selects the dominant answer from between the two answers, using non-dominated relations.

\subsubsection{Particles position update}

In this part, genetic algorithm operators are used to updating the particles. The method of updating the particles is as follows (Tavakoli Moghadam et al., 2011):

$$
x_{i}^{t+1}=\left(x_{i}^{t}-p_{i}^{t}\right)+\left(x_{i}^{t}-p_{g}^{t}\right)+\overline{x_{i}^{t}}
$$

$x_{i}^{t+1}$ is the position of particle " $\mathrm{i}$ " in iteration $\mathrm{t}+1, x_{i}^{t}$ is the position of particle " $\mathrm{i}$ " in iteration $\mathrm{t}, p_{i}^{t}$ is the best solution that particle " $i$ " has achieved up to the current generation, $p_{g}^{t}$ is the best solution of all iterations, $\overline{x_{l}^{t}}$ is a neighborhood of $x_{i}^{t}$ that has generated by mutation operator, “_“ is the sign of crossover, and "+” is the sign of selection operator. To achieve "i"th solution in iteration $t+1,5$ solutions are generated: Two are the results of crossover operator between $x_{i}^{t}$ and $p_{i}^{t}$, two are the results of crossover operator on $x_{i}^{t}$ and $p_{g}^{t}$ and one is the result of the actions of the mutation operator on $x_{i}^{t}$. Finally, from among these 5 answers, the one that has the higher quality and dispersion is chosen as $x_{i}^{t+1}$. In fact, it is used in this formula and as a guide to reaching the next iteration answers.

\subsubsection{Crossover operator}

The crossover operator designed in this algorithm is a single point type. After the two parents are given as the input to the crossover operator, the location matrices of each parent's distribution centers will be selected for the crossover operation. The operation of the crossover is as follows: Location matrix: An index k is randomly selected in a uniform interval $[1, \mathrm{~K}]$ ( $\mathrm{K}$ is the number of distribution centers). Then the two matrices yk1 (first parent) and yk2 (second parent) are combined as a single point intersection, and two new child matrices are generated that represent the location of the distribution centers. Single point crossover: Suppose the two following matrices and index 3 are the input of a single point crossover:

\begin{tabular}{|l|l|l|l|l|l|l|l|l|}
\hline 0 & 1 & 0 & 1 & 0 & 0 & 1 & 1 \\
\hline 1 & 1 & 0 & 0 & 1 & 0 & 1 & 0 \\
\hline
\end{tabular}

These two matrices are parent 1 and parent 2, now two children are created using a single point crossover as follows from these two parents. The first 3 houses of the first parent are inherited by the first child and also the first child gets the last 5 houses from the second parent. The second child is formed like the first child, with the difference that he inherits the first three houses from the second parent and the last 5 houses from the first parent. The first child will be according to the following matrix.

\begin{tabular}{|l|l|l|l|l|l|l|l|l|}
\hline 0 & 1 & 0 & 0 & 1 & 0 & 1 & 0 \\
\hline 1 & 1 & 0 & 1 & 0 & 0 & 1 & 1 \\
\hline
\end{tabular}




\subsubsection{Mutation operator}

The mutation operator used in this algorithm for updating the particles is the same as VNS. (Roshanaei et al. 2009).

\subsubsection{Pareto archive update}

In the proposed algorithm, a set called Pareto archive is considered, which holds the non-dominated solutions generated by the algorithm. This set will be updated each time the algorithm is replicated. The method of updating is that the answers produced in it are repeated and the answers in the Pareto archive are poured into a pool of answers and leveled together, then among these answers, the solutions in the first level or the non-dominated solutions are selected and considered as the new Pareto archive.

\subsubsection{Selection of solutions}

In each iteration, the algorithm needs a set of answers. To select the next iteration population, the existing answers in that iteration population and the new answers generated by the algorithm are poured together in an answer pool and after leveling and calculating the crowding distance for each answer according to the level of that answer, using the rule of Deb et al. (2009), "n" answers with the highest quality and highest dispersion are selected as the population of the next iteration of the algorithm.

\subsubsection{Tuning of the parameters}

Parameters of the algorithm are tuned to assure the performance quality of the algorithm. In doing so, the Taguchi method based on the design of experiments (DOE) in Minitab software is presented to evaluate the impact of changes in input variables on response variables. Population size, VNS iteration, and algorithm iteration for MOPSO and population size, mutation rate, crossover rate, and algorithm iteration for NSGA-II are the input variables. Table (11) presents the MOPSO and NSGA-II parameters in 3 levels.

Table12. MOPSO and NSGA-II parameters

\begin{tabular}{|l|l|l|l|l|}
\hline Algorithms & Parameters & Level 1 & Level 2 & Level 3 \\
\hline \multirow{4}{*}{ MOPSO } & Population size & 70 & 150 & 200 \\
\cline { 2 - 5 } & VNS iteration & 5 & 10 & 15 \\
\cline { 2 - 6 } & Algorithm iteration & 150 & 300 & 500 \\
\hline \multirow{4}{*}{ NSGA-II } & Population size & 70 & 150 & 200 \\
\cline { 2 - 6 } & mutation rate & 0.006 & 0.009 & 0.01 \\
\cline { 2 - 5 } & crossover rate & 0.75 & 0.85 & 0.95 \\
\cline { 2 - 5 } & Algorithm iteration & 150 & 300 & 500 \\
\hline
\end{tabular}

In the DOE strategy, some factors are changed at a time to specify the interaction and impact of each factor

(Babaveisi et al., 2018). To make the computation easier, L9 orthogonal arrays are presented for both algorithms in 
tables (13) and (14) which are resulted from Minitab software and present the number of experiments with consideration of factors.

After calculation of GAP criterion as shown in eq. (32), signal to noise $(\mathrm{S} / \mathrm{N})$ ratio and means of means which are of the Taguchi analysis methods are presented in charts 1 to 4 to specify the stages of the algorithms.

GAP $=\frac{X-Y}{Y} \quad$ (X: Present solution, $\mathrm{Y}:$ Best Solution $)$

Table 13. Orthogonal table for MOPSO

\begin{tabular}{|c|c|c|c|c|}
\hline Experiment no. & VNS iteration & Population size & $\begin{array}{c}\text { Algorithm } \\
\text { iteration }\end{array}$ & GAP \\
\hline L1 & 5 & 70 & 150 & 0.815 \\
\hline L2 & 5 & 150 & 300 & 0.906 \\
\hline L3 & 5 & 200 & 500 & 0.127 \\
\hline L4 & 10 & 70 & 300 & 0.99 \\
\hline L5 & 10 & 150 & 500 & 0.632 \\
\hline L6 & 10 & 200 & 150 & 0.098 \\
\hline L7 & 15 & 70 & 500 & 0.278 \\
\hline L8 & 15 & 150 & 150 & 0.547 \\
\hline L9 & 15 & 200 & 300 & 0.958 \\
\hline
\end{tabular}

Table 14. Orthogonal table for NSGA-II

\begin{tabular}{|c|c|c|c|c|c|}
\hline Experiment no. & Crossover rate & $\begin{array}{c}\text { Population } \\
\text { size }\end{array}$ & Mutation rate & $\begin{array}{c}\text { Algorithm } \\
\text { iteration }\end{array}$ & GAP \\
\hline L1 & 0.75 & 70 & 0.006 & 150 & 0.965 \\
\hline L2 & 0.85 & 150 & 0.009 & 300 & 0.158 \\
\hline L3 & 0.95 & 200 & 0.01 & 500 & 0.971 \\
\hline L4 & 0.75 & 70 & 0.009 & 500 & 0.957 \\
\hline L5 & 0.85 & 150 & 0.01 & 150 & 0.485 \\
\hline L6 & 0.95 & 200 & 0.006 & 300 & 0.800 \\
\hline L7 & 0.75 & 70 & 0.01 & 300 & 0.142 \\
\hline L8 & 0.85 & 150 & 0.006 & 500 & 0.422 \\
\hline L9 & 0.95 & 200 & 0.009 & 150 & 0.967 \\
\hline
\end{tabular}



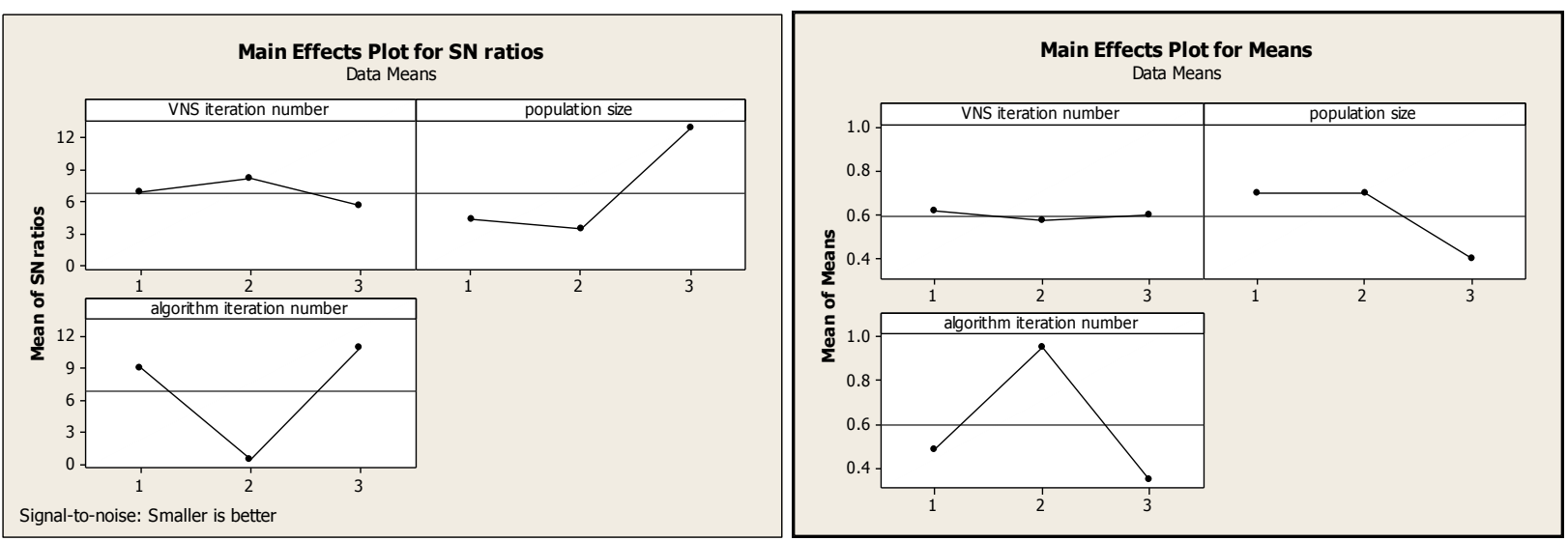

Chart 1 \& 2. S/N ratio and Means of Means for MOPSO
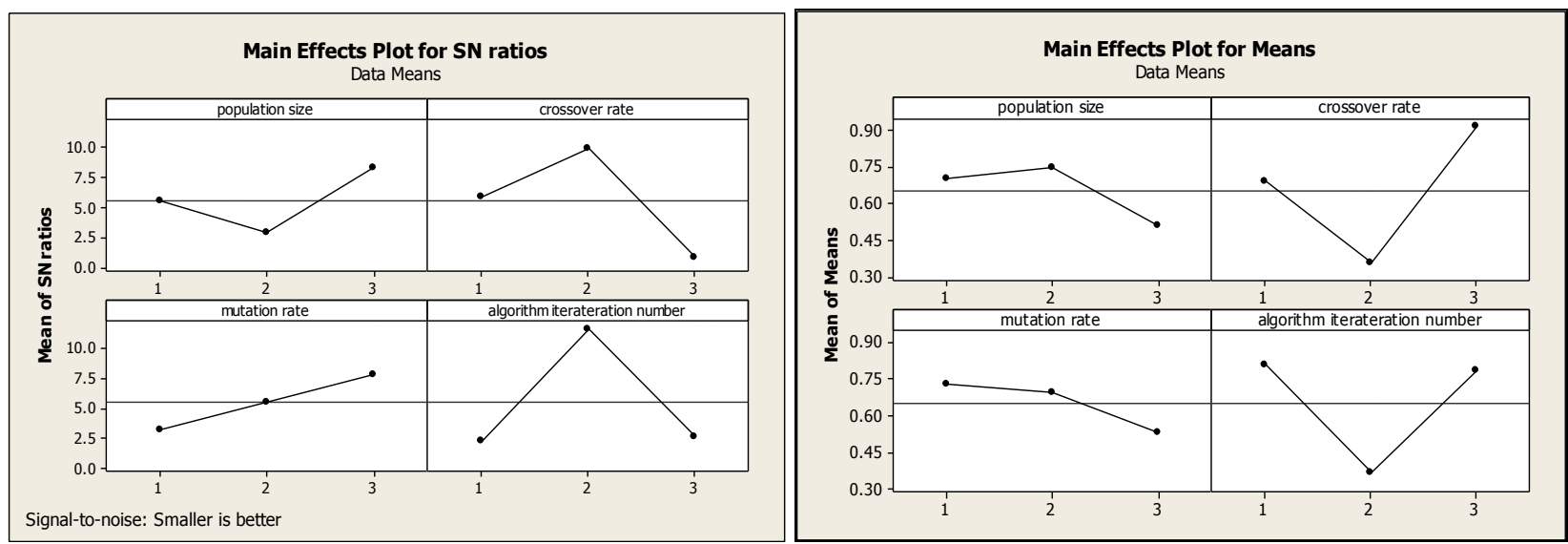

Chart $3 \&$ 4. S/N ratio and Means of Means for MOPSO

As can be seen in charts 1 to 4, for MOPSO Population size at level 2, algorithm iteration at level 2, and VNS iteration at level 3 are effective. In other words, the population size of 150, VNS iteration of 15, and algorithm iteration of 300 are considered. Besides, for NSGA-II, population size at level 3 equals 200, algorithm iteration at level 2 equals 300, mutation rate at level 3 equals 0.01 , and crossover rate at level 2 equals 0.85 are effective.

\subsubsection{Comparison indices of the algorithms}

In this paper, 3 indices are utilized to compare the performance of the algorithms to check which algorithm presents better results toward quality, uniformity, and dispersion indices.

- Quality index levels the Pareto solutions resulted from both algorithms and checks how many of the level-1 solutions belong to each algorithm. The higher the number of level-1 solutions belongs to an algorithm, the higher the quality of the algorithm.

- Uniformity index which is responsible to check the Pareto solutions at the solution boundary, defines as follows:

$U=\frac{\sum_{i=1}^{N-1}\left|d_{\text {mean }}-d_{i}\right|}{(N-1) \times d_{\text {mean }}}$

(Where $d_{i}$ is Euclidean distance between two non-dominated neighboring solutions, and $d_{\text {mean }}$ is the mean of $d_{i}$ ). 
- Dispersion index determines the number of non-dominated solutions on the optimal boundary and is as follows:

$D=\sqrt{\sum_{i=1}^{N} \max \left(\left\|x_{t}^{i}-y_{t}^{i}\right\|\right)}$

(Where $\left\|x_{t}^{i}-y_{t}^{i}\right\|$ is the Euclidean distance between $x_{t}^{i}$ and $y_{t}^{i}$, which are two neighboring solutions on the optimal boundary.

\subsubsection{Sample problems}

To validate the model with proposed algorithms and comparison indexes, sample problems with small to large size categorization are designed and in doing so parameters such as product, planning period, supplier, and manufacturer quantities are fixed but DC and consumer quantities are varied in a way which DC quantities from small to the large size ranges from 2 to 60 , whereas consumer quantities are considered from 10 to 130 .

As an example of how these problems are designed, Table (15) illustrates the considered problems for a large size level.

Table 15. large-sized problems

\begin{tabular}{|c|c|c|c|c|c|c|}
\hline Problem no. & $\begin{array}{c}\text { Product } \\
\text { quantity }\end{array}$ & $\begin{array}{c}\text { Period } \\
\text { quantity }\end{array}$ & $\begin{array}{c}\text { Supplier } \\
\text { quantity }\end{array}$ & $\begin{array}{c}\text { Manufacturer } \\
\text { quantity }\end{array}$ & DCs quantity & $\begin{array}{c}\text { Consumer } \\
\text { quantity }\end{array}$ \\
\hline 1 & 8 & 12 & 5 & 6 & 20 & 120 \\
\hline 2 & 8 & 12 & 5 & 6 & 30 & 120 \\
\hline 3 & 8 & 12 & 5 & 6 & 40 & 120 \\
\hline 4 & 8 & 12 & 5 & 6 & 50 & 120 \\
\hline 5 & 8 & 12 & 5 & 6 & 30 & 130 \\
\hline 6 & 8 & 12 & 5 & 6 & 40 & 130 \\
\hline 7 & 8 & 12 & 5 & 6 & 50 & 130 \\
\hline 8 & 8 & 12 & 5 & 6 & 60 & 130 \\
\hline 9 & 8 & 12 & 5 & 6 & & \\
\hline
\end{tabular}

\section{Results and Conclusion}

\subsection{Computational results}

Considering the data gathered in part 4 of this paper and the two meta-heuristic algorithm methods, these have been coded in MATLAB software, version R2015a, on a laptop with 10GB of RAM and Intel core i7 CPU. Based on the parameters which have been set and the sample problems which have been presented in the previous part, objective function results and comparison indexes for big-sized problems are presented in Tables (16) and (17). 
Table 16. Objective function value resulted from solving large-sized problems

\begin{tabular}{|c|c|c|c|c|c|c|}
\hline \multirow{2}{*}{ Problem } & \multicolumn{5}{|c|}{ MOPSO } & \multicolumn{3}{c|}{ NSGA-II } \\
\cline { 2 - 7 } & $Z_{1}$ & $Z_{2}$ & $Z_{3}$ & $Z_{1}$ & $Z_{2}$ & $Z_{3}$ \\
\hline 1 & 565839245.1 & 38099634.1 & 441600354.7 & 989759968.2 & 38893354.5 & 406283730.1 \\
\hline 2 & 2186661125.4 & 39852907.7 & 474894853.5 & 2389521603.2 & 39090004.6 & 413892170.6 \\
\hline 3 & 2249497810.1 & 45255970.4 & 533228058.4 & 2404974865.9 & 45725051.5 & 428734134.7 \\
\hline 4 & 2804767718.8 & 45407888.7 & 550481989.9 & 2924790091.3 & 45369729.1 & 506203679.9 \\
\hline 5 & 2879709021.1 & 46023234.1 & 609840026.8 & 3111989658.7 & 46222933.2 & 571947954.6 \\
\hline 6 & 3034151605.6 & 47198068.2 & 620320025.7 & 34681495955.8 & 48376334.2 & 604457426.4 \\
\hline 7 & 3501975245.8 & 47247066.9 & 630528487.6 & 3896663623.5 & 49808768.5 & 617794902.3 \\
\hline 8 & 4001978419.9 & 58632158.5 & 656893816.3 & 4504607524.3 & 53145430.9 & 644931275.2 \\
\hline 9 & 4318171862.7 & 63073004.5 & 689713714.4 & 5049330527.9 & 62996416.3 & 647307516.4 \\
\hline
\end{tabular}

Table 17. Indexes comparison results for big-sized problems

\begin{tabular}{|c|c|c|c|c|c|c|}
\hline \multirow{2}{*}{ Problem } & \multicolumn{3}{|c|}{ MOPSO } & \multicolumn{3}{c|}{ NSGA-II } \\
\cline { 2 - 7 } & Quality & Uniformity & Diversity & Quality & Uniformity & Diversity \\
\hline 1 & 90 & 0.75 & 2871.6 & 10 & 0.74 & 1901.6 \\
\hline 2 & 85.9 & 1.72 & 2685.3 & 14.1 & 0.64 & 1954.2 \\
\hline 3 & 87.6 & 1.67 & 3063.5 & 12.4 & 0.76 & 2112.5 \\
\hline 4 & 70.9 & 0.73 & 2636.3 & 29.1 & 0.65 & 1901.9 \\
\hline 5 & 89.9 & 0.71 & 2816.5 & 10.1 & 0.70 & 2265.1 \\
\hline 6 & 66.8 & 1.70 & 3486.3 & 33.2 & 0.54 & 2793.6 \\
\hline 7 & 87.2 & 1.17 & 4121.9 & 12.8 & 0.65 & 3278.6 \\
\hline 8 & 100 & 1.13 & 4565.9 & 0 & 0.64 & 3397.7 \\
\hline 9 & 88.4 & 1.04 & 5054.1 & 11.6 & 0.73 & 4758.7 \\
\hline
\end{tabular}

As can be seen in the tables above which are presented for big-sized problems as a sample, in all problems of small, medium, and large-sized, the value of quality and diversity indexes obtained for the MOPSO algorithm is greater than the values calculated for the NSGA-II algorithm, which indicates the higher ability of MOPSO algorithm to achieve a near-optimal solution as well as the higher capability to explore and extract the possible area of the 
answer, compared to the NSGA-II. The value of the uniformity index also indicates that in most cases, the NSGA-II algorithm searches the response area more uniformly. Besides, solving time by the MOPSO algorithm is longer than the NSGA-II algorithm in all cases, which means that the MOPSO algorithm needs more time to solve these problems than the NSGA-II. It should be noted that as the size of the problem increases, the solution time of the algorithm changes increasingly, and the time to solve large-scale problems is much higher than for small and medium-sized problems, which indicates that the problem is difficult. The diagram below shows a comparison of the execution times of the two algorithms for all problems.

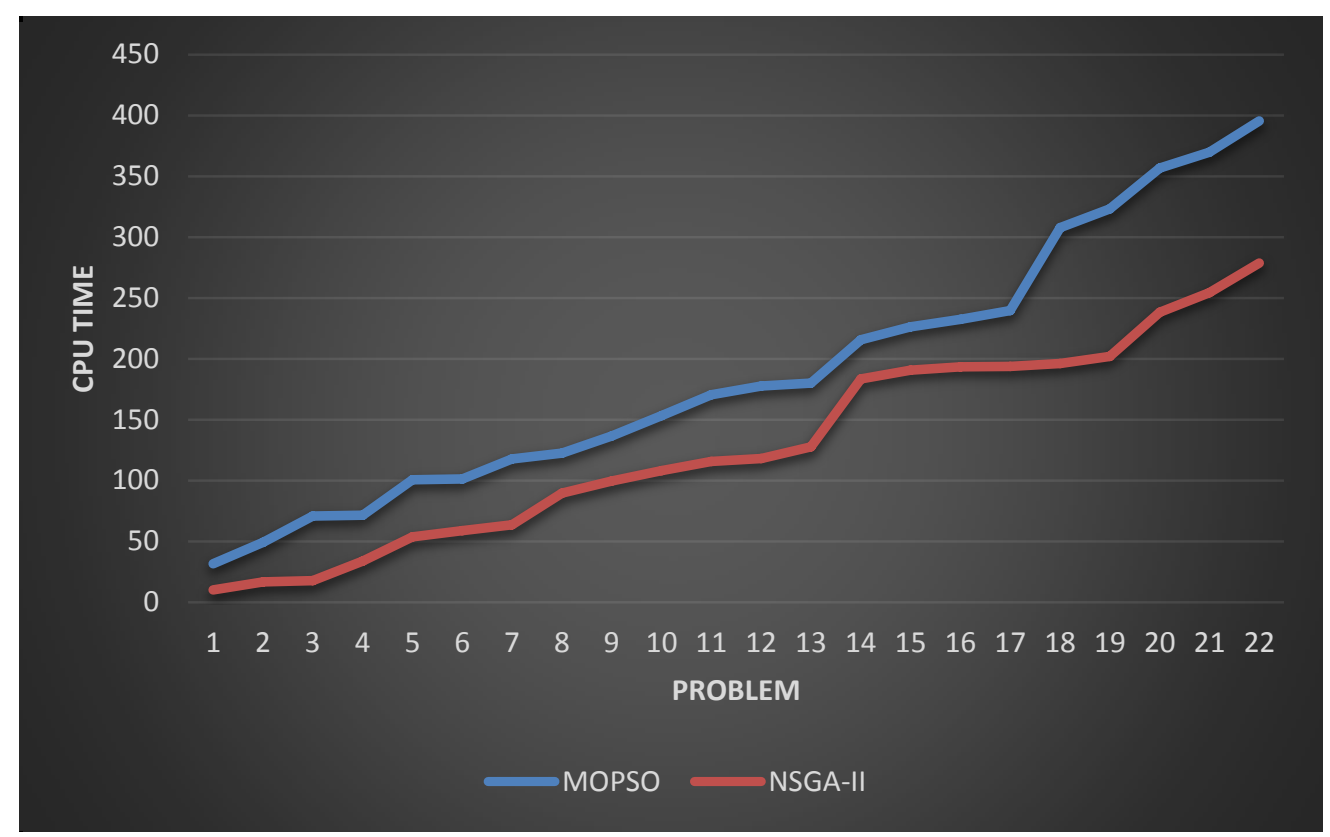

Figure (1). CPU time to run the algorithms

\subsection{Conclusion}

In this paper, a multi-objective optimization model has been proposed regarding the most critical priorities of the manufacturers in the case study of our research, which are the minimization of costs, lead-time, and risks. Hence, the objectives come true on the condition that a new product launches. After outlining the most important NPD criteria, ranking the manufacturers, and identifying the risks threatening the NPD process of the Iranian UPVC profile industry, two practical meta-heuristic algorithms, MOPSO and NSGA-II, were utilized to solve the model. Comparison indexes are employed to assess the performance of both algorithm methods.

The outputs revealed that production cost is the most crucial criterion that makes the manufacturers launch the new product, introduced in this paper. Besides, based on the fuzzy-TOPSIS method, "manufacturer A" has the highest ranking among the other leading manufacturers of this industry. Finally, the performance comparison of the algorithms revealed that MOPSO has the higher capability to search the answer in the feasible area and find qualified solutions, which is why the run-time of this method is more extended than NSGA-II.

For future research, we recommend that the proposed model with different objectives be utilized for petrochemical companies which are the main upstream of the UPVC profile industry. Furthermore, other algorithms like SA or $\mathrm{CE}$ be used as the second algorithm to be compared with the performance of MOPSO. 
Asian Journal of Basic Science \& Research

Volume 3, Issue 3, Pages 65-92, July-September 2021

Declarations

\section{Source of Funding}

This research did not receive any grant from funding agencies in the public, commercial, or not-for-profit sectors.

\section{Competing Interests Statement}

The authors declare no competing financial, professional and personal interests.

\section{Consent for publication}

Authors declare that they consented for the publication of this research work.

Availability of data and material

Authors are willing to share data and material according to the relevant needs.

\section{References}

Aqlan, F., \& Lam, S. S. (2016). Supply chain optimization under risk and uncertainty: A case study for high-end server manufacturing. Computers \& Industrial Engineering, 93, 78-87.

Babaveisi, V., Paydar, M. M., \& Safaei, A. S. (2018). Optimizing a multi-product closed-loop supply chain using NSGA-II, MOSA, and MOPSO meta-heuristic algorithms. J. of Industrial Engineering Int., 14(2), 305-326.

Bouncken, R. B., Fredrich, V., Ritala, P., \& Kraus, S. (2018). Coopetition in new product development alliances: advantages and tensions for incremental and radical innovation. British Journal of Management, 29(3), 391-410.

Brandenburg, M. (2015). Low carbon supply chain configuration for a new product-a goal programming approach. International Journal of Production Research, 53(21), 6588-6610.

Chang, W., \& Taylor, S. A. (2016). The effectiveness of customer participation in new product development: A meta-analysis. Journal of Marketing, 80(1), 47-64.

Chaudhuri, A., Mohanty, B. K., \& Singh, K. N. (2013). Supply chain risk assessment during new product development: a group decision-making approach using numeric and linguistic data. International Journal of Production Research, 51(10), 2790-2804.

Chauhan, A. S., Yadav, O. P., Soni, G., \& Jain, R. (2017). A holistic approach to manage risks in NPD process. 2017 Annual Reliability and Maintainability Symposium (RAMS).

Chen, S.-J., \& Hwang, C.-L. (1992). Fuzzy multiple attribute decision making methods. Fuzzy multiple attribute decision making, 289-486.

Chen, Y.-W., Wang, L.-C., Wang, A., \& Chen, T.-L. (2017). A particle swarm approach for optimizing a multi-stage closed loop supply chain for the solar cell industry. Robotics and Computer-Integrated Manufacturing, $43,111-123$. 
Asian Journal of Basic Science \& Research

Volume 3, Issue 3, Pages 65-92, July-September 2021

Cooper, R. G. (2019). The drivers of success in new-product development. Industrial Marketing Management, 76, $36-47$.

Deb, K., Gupta, S., Daum, D., Branke, J., Mall, A. K., \& Padmanabhan, D. (2009). Reliability-based optimization using evolutionary algorithms. IEEE Transactions on Evolutionary Computation, 13(5), 1054-1074.

Deb, K. (2001). Nonlinear goal programming using multi-objective genetic algorithms. Journal of the Operational Research Society, 52(3), 291-302.

Dehdar, E., Azizi, A., \& Aghabeigi, S. (2018). Supply chain risk mitigation strategies in automotive industry: A review. 2018 IEEE International Conference on Industrial Engineering and Engineering Management (IEEM),

Fahimnia, B., Davarzani, H., \& Eshragh, A. (2018). Planning of complex supply chains: A performance comparison of three meta-heuristic algorithms. Computers \& Operations Research, 89, 241-252.

Felfel, H., Ayadi, O., \& Masmoudi, F. (2016). Multi-objective stochastic multi-site supply chain planning under demand uncertainty considering downside risk. Computers \& Industrial Engineering, 102, 268-279.

Gao, J., \& Bernard, A. (2018). An overview of knowledge sharing in new product development. The International Journal of Advanced Manufacturing Technology, 94(5), 1545-1550.

Gmelin, H., \& Seuring, S. (2014). Determinants of a sustainable new product development. Journal of Cleaner production, 69, 1-9.

Hilletofth, P., Reitsma, E., \& Eriksson, D. (2018). Coordination of new product development and supply chain management. In Innovation and Supply Chain Management (pp. 33-50). Springer.

Hasanzadeh, H., \& Seifbarghy, M. (2018). Designing a three layer supply chain considering different transportation channels and delivery time dependent demand. International Journal of Industrial Engineering, $25(3)$.

Huang, Z., Yu, H., Chu, X., \& Peng, Z. (2017). A goal programming based model system for community energy plan. Energy, 134, 893-901.

Jafarian, M., \& Bashiri, M. (2014). Supply chain dynamic configuration as a result of new product development. Applied Mathematical Modelling, 38(3), 1133-1146.

Javanshir, H., Ebrahimnejad, S., \& Nouri, S. (2012). Bi-objective supply chain problem using MOPSO and NSGA-II. International Journal of Industrial Engineering Computations, 3(4), 681-694.

Jones, D., \& Tamiz, M. (2016). A review of goal programming. Multiple criteria decision analysis, 903-926.

Lawson, B., Krause, D., \& Potter, A. (2015). Improving supplier new product development performance: the role of supplier development. Journal of Product Innovation Management, 32(5), 777-792.

Markham, S. K., \& Lee, H. (2013). Product Development and Management Association's 2012 Comparative Performance Assessment Study. Journal of Product Innovation Management, 30(3), 408-429. 
Pasandideh, S. H. R., Niaki, S. T. A., \& Asadi, K. (2015). Bi-objective optimization of a multi-product multi-period three-echelon supply chain problem under uncertain environments: NSGA-II and NRGA. Information Sciences, $292,57-74$.

Roshanaei, V., Naderi, B., Jolai, F., \& Khalili, M. (2009). A variable neighborhood search for job shop scheduling with set-up times to minimize makespan. Future Generation Computer Systems, 25(6), 654-661.

Tang, C. S., Zimmerman, J. D., \& Nelson, J. I. (2009). Managing new product development and supply chain risks: The Boeing 787 case. Supply Chain Forum: An International Journal,

Tavakkoli-Moghaddam, R., Azarkish, M., \& Sadeghnejad-Barkousaraie, A. (2011). A new hybrid multi-objective Pareto archive PSO algorithm for a bi-objective job shop scheduling problem. Expert Systems with Applications, 38(9), 10812-10821.

Yan, T., \& Dooley, K. (2014). Buyer-supplier collaboration quality in new product development projects. Journal of Supply Chain Management, 50(2), 59-83. 